\title{
Análise Reparável e Irreparável: o Conceito Psicanalítico de Reparação na Agenda da Transição Brasileira
}

\author{
Rafael Alves Lima \\ Universidade de São Paulo, SP, Brasil.
}

\begin{abstract}
Resumo: O presente trabalho visa estabelecer uma reflexão crítica acerca do emprego do conceito psicanalítico de reparação pela agenda da Justiça de Transição no Brasil. Por meio de uma recuperação da gênese do conceito de reparação em psicanálise, primeiramente é retomado o princípio norteador da reparação em referência ao conceito do trauma em Freud e em Ferenczi, para então lançar luz sobre Klein e a tradição do pós-kleinismo que consagrariam o conceito de reparação em psicanálise, matizando diferenças em relação à perspectiva da irreparabilidade em Lacan. Posteriormente, discute-se os modos pelos quais a dimensão reparatória se destina à história, na medida em que o reconhecimento social da experiência traumática se torna possível pela função do testemunho, expediente por excelência de crítica ao revisionismo. Por fim, conclui-se dispondo elementos para a proposta de reparação psíquica na Justiça de Transição brasileira segundo o legado psicanalítico, tendo em vista a importância da assimilação do papel do objeto em psicanálise nas diferentes matrizes que esta reflexão inspira no que diz respeito à compreensão do tratamento analítico.
\end{abstract}

Palavras-chave: Reparação, Psicanálise, Transição, História, Brasil.

\section{Reparable and Irreparable Analysis: The Psychoanalytic Concept of Reparation in the Agenda of the Brazilian Transition}

\begin{abstract}
This paper aims to establish a critical reflection on the use of the psychoanalytic concept of reparation by the Transitional Justice agenda in Brazil. Through a recovery of the genesis of the concept of reparation in psychoanalysis, the guiding principle of reparation in relation to the concept of trauma in Freud and in Ferenczi is first taken up, to shed light on Klein and the tradition of post-Kleinism that would consecrate the concept of reparation in psychoanalysis, making a difference in relation to the perspective of irreparability in Lacan. Subsequently, it discusses the ways in which the reparatory dimension is intended for history, insofar as the social recognition of the traumatic experience is made possible by the function of testimony, the expedient par excellence of criticism of revisionism. Finally, it is concluded by ordaining elements for the proposal of psychic reparation in the Brazilian Transitional Justice according to the psychoanalytic legacy, considering the importance of the assimilation of the role of the object in psychoanalysis in the different matrices that this reflection inspires with regard to the understanding of the analytical treatment.
\end{abstract}

Keywords: Reparation, Psychoanalysis, Transition, History, Brazil. 


\title{
Análisis Reparable e Irreparable: el Concepto Psicoanalítico de Reparación en la Agenda de la Transición Brasileña
}

\begin{abstract}
Resumen: El presente trabajo busca establecer una reflexión crítica acerca del empleo del concepto psicoanalítico de reparación por la agenda de la Justicia de Transición en Brasil. Por medio de una recuperación de la génesis del concepto de reparación en psicoanálisis, primero se reanuda el principio orientador de la reparación en referencia al concepto del trauma en Freud y en Ferenczi, para entonces arrojar luz sobre Klein y la tradición del post-kleinismo que consagrarían el concepto de reparación en psicoanálisis, matizando diferencias en relación a la perspectiva de la irreparabilidad en Lacan. Posteriormente, se discuten los modos por los cuales la dimensión reparadora se destina a la historia, en la medida en que el reconocimiento social de la experiencia traumática se torna posible por la función del testimonio, expediente por excelencia de crítica al revisionismo. Por último, se concluye disponiendo elementos para la propuesta de reparación psíquica en la Justicia de Transición brasileña según el legado psicoanalítico, teniendo en vista la importancia de la asimilación del papel del objeto en psicoanálisis en las diferentes matrices que esta reflexión inspira en lo que se refiere a la comprensión del tratamiento analítico.
\end{abstract}

Palabras clave: Reparación, Psicoanálisis, Transición, Historia, Brasil.

\section{Introdução}

As Clínicas do Testemunho, da Comissão de Anistia do Ministério da Justiça do Governo Federal, têm o objetivo de promover a reparação psíquica das vítimas de violações de direitos humanos ocorridas durante a ditadura civil-militar brasileira (1964-1985). Graças a esta iniciativa desbravadora e pioneira na história do nosso país, familiares de mortos e desaparecidos políticos, torturados, presos e exilados receberiam assim um inédito tratamento psicológico no Brasil, com a finalidade de tratar os danos psíquicos causados pela violência de Estado promovida no período histórico referido.

Tais medidas têm o nome de reparação psíquica. Promovidas desde o interior do Estado, elas são balizadas desde complexas zonas de fronteira entre o campo social, histórico e político e o campo clínico, no que se refere ao tratamento psicológico individual ou em grupo. De acordo com o Presidente da Comissão da Anistia, Paulo Abraão, e com o Coordenador-Geral de Memória Histórica desta mesma Comissão, Marcelo Torelly,

o processo de reparação às vítimas foi o eixo estruturante da justiça de transição no Brasil. [...] Seu fluxo de seguimento nunca cessou e desenvolveu-se gradualmente, com o somatório de forças ocorrendo justamente à medida que o processo de reparação corroía dois dos pilares de sustentação da estratégia de saída do regime (a negação da existência de vítimas e a imposição do esquecimento) (Abrão, \& Torelly, 2012, p. 192).

Vale notar que a ênfase conferida ao caráter estruturante e central do processo de reparação se desdobra em duas constatações capitais: 1) a de que era imprescindível reconhecer que as violações contra os direitos humanos promovidas pelo Estado ditatorial não eram ficções inventadas por um ou outro setor de nossa sociedade, mas sim que elas existiram concretamente; e 2) a de que as condições para conferir realidade a essas existências seriam dadas pelas categorias da memória e do reconhecimento.

Será preciso, destarte, introduzir a interface psicanalítica desta discussão desde ao menos duas ordens. Uma primeira é instaurar a reflexão em que o conceito psicanalítico de reparação vem a informar sobre a proposta de reparação psíquica na Justiça de Transição. Uma segunda ordem é buscar compreender como os dois conceitos, diferentes em suas origens epistêmicas, convergem em uma proposta de manifestação das experiências subjetivas na superfície da história. Por fim, levantaremos a tese de como a história, sendo então o receptáculo final dos testemunhos individuais do sofrimento, acaba por ser o solo do reconhecimento social da incidência do trauma, lá 
onde a reflexão deve se direcionar à não repetição das graves violações de direitos humanos do período ditatorial na transição para a democracia.

\section{Raízes e ramificações do conceito de reparação em psicanálise}

Para qualquer psicanalista, é quase imediata a constatação de que o conceito de reparação se tornará consagrado pela psicanalista Melanie Klein, que o formula com o objetivo de delinear a relação que a criança estabelece com os objetos na constituição subjetiva. A origem do conceito de reparação em psicanálise remete a dois termos presentes no alemão de Freud: Wiederherstellung (restauração ou restabelecimento) e Wiedergutmachung (restituição ou reparação). Wiederherstellung refere-se tanto ao sentido médico de se restabelecer de uma doença quanto no sentido técnico (restabelecer uma conexão perdida, por exemplo); Stellen no alemão remete a "lugar", "posição", enquanto a forma Herstellung significa fabricação, produção, construção. Assim, Wiederherstellung aponta para o reconstruir enquanto um processo, para um "deixar em ordem novamente". Já Wiedergutmachung significa, literalmente, "fazer de novo o bom": ung é a partícula, também presente no primeiro termo, que designa o devir, a "fazência"; mach é "fazer", gut é "bem" ou "bom", enquanto Wieder é o "de novo". Há um sentido transitivo de "fazer o bem" (gutmachung) que o primeiro não tem, além do sentido de restituir uma perda. Este último termo ficou bem marcado depois da II Guerra Mundial, porque é como ficou conhecida a ação com a qual o governo alemão teve de se comprometer para indenizar aqueles que foram atingidos severamente pelo Holocausto $^{1}$. Ou seja, enquanto Wiederherstellen aponta para o tornar ao que era antes, ou tomar o processo de restabelecimento como construção, Wiedergutmachen designa a reparação propriamente dita, no que se refere a restituir algo perdido, mas levando em conta o que há nisso de irreparável.

Ou seja, já no início do presente artigo nos vemos diante de um impasse absolutamente nobre no que se refere à conceitografia psicanalítica: primeiramente, não é possível compreender o mecanismo de reparação sem compreender a natureza e a função do objeto referido neste processo - contendo aqui toda a variedade do uso do objeto que compõe a experi- ência intelectual de Freud; consequentemente, é preciso compreender que, em termos da direção da cura psicanalítica, a reparação aponta para uma dimensão intersubjetiva, uma vez que reparar-se-ia por meio do outro, ou com o outro. Isso por si só pauta os diferentes programas clínicos da psicanálise e suas respectivas concepções de transferência - ou seja, da qualidade do laço entre analista e analisando. A aposta transferencial, comum a todo e qualquer tratamento psicanalítico, se dá e se confirma na medida em que o analista ocupa a posição de objeto para o analisando na condução de uma análise. No entanto, cada qual dará um destino a essa premissa geral; serão as diferentes matrizes metapsicológicas, teóricas e epistêmicas que darão curso a diferentes concepções de tratamento e de cura, a depender da tradição psicanalítica a qual se está inclinado. Ou seja: muito rapidamente chega-se à constatação de que, no limite, problematizar o conceito de reparação em psicanálise implica em compreender o que cada autor chama de objeto.

\section{Método}

Sem recuar diante deste impasse, impõe-se aqui o desafio de apresentar minimamente este largo panorama sob o ângulo do conceito de reparação. Não obstante, todo e qualquer empenho para operar distinções, promover agrupamentos e sistematizar categorias conceituais do campo psicanalítico é e será, tão somente, (mais) um modo de fazê-lo. Há no campo da história e da historiografia da psicanálise inúmeros esforços nesse sentido com o objetivo de estabelecer linhas gerais de diferenciação entre as ditas escolas psicanalíticas, ou seja, naquilo que se refere ao entendimento dos motivos pelos quais uma determinada escola toma um certo rumo em seu processo de teorização, enquanto outra escola escolhe outro caminho. Uma vez tomados os tensionamentos em torno do conceito de reparação como nosso eixo central - portanto, em detrimento de outros eixos possíveis -, opta-se aqui pelo método da genealogia conceitual, que busca recuperar a gênese do conceito percorrendo os movimentos de sua evolução em seus diferentes usos e atributos na história da disciplina, bem como a serviço de que ele se presta em sua terminação clínica e prática. Um exemplo que pode ser recuperado na esteira deste método é $O$ tronco $e$ os ramos de Mezan (2014). Nele são apresentadas algu-

${ }^{1}$ A este respeito, conferir Ludi, 2012. 
mas hipóteses que decompõem o modelo das "relações objetais" e o modelo "estrutural-pulsional". É a chamada escola inglesa da psicanálise capitaneada pelo kleinismo, destacada nos anos 1940 do annafreudismo e que contempla ainda o chamado Middlegroup, aquela ficou também conhecida como a escola das "relações de objeto". Sob esta denominação se incluem movimentos díspares, desde aqueles que se colocam ao lado de uma finalidade adaptacionista do tratamento psicanalítico, cujas possibilidades de integração dos elementos estranhos ao psiquismo encontrem seu recinto no alargamento das funções do eu, até aqueles que se dedicaram à compreensão do itinerário do desenvolvimento emocional, da maturação subjetiva e do crescimento. A experiência francesa, cuja expressão maior se concentra no ensino de Jacques Lacan, por sua vez, se mostrou crítica em relação às finalidades clínicas contidas na ideia de reparação.

Analisaremos adiante como serão mobilizados conceitos diversos nestas linhagens, referidos a Freud cada qual de uma maneira, incutindo-lhe uma determinada leitura, sem que uma seja "mais correta" ou "mais verdadeira" do que outra, mas nos posicionando em relação a elas. Parte-se aqui da premissa de que o conceito de reparação não pode ser pensado, primeiro, sem mobilizar diferenças de natureza e função do objeto, diferenças das matrizes epistêmicas que dão ensejo a uma ou outra leitura do texto freudiano, diferenças da concepção de intersubjetividade, diferenças de programas clínicos. Ou seja, reparação é um conceito tão polifônico quanto são estes que necessariamente o acompanham na diversidade da psicanálise. Não é sequer possível falar, já apontando um paradoxo em nosso próprio título: não há $u m$ conceito de reparação unívoco e contínuo na psicanálise; dever-se-ia, de início, ou falar no plural ("nas psicanálises"), ou se perguntar com a devida franqueza: "em qual psicanálise?".

\section{Trauma, reparação e fim de análise: de Freud a Ferenczi, de Ferenczi a Freud}

A concepção freudiana de trauma é tão central para a psicanálise que ela se confunde com o seu próprio nascimento. É de Charcot que Freud retira a ideia de "origem traumática" para pensar na causalidade dos sintomas histéricos a partir da vivência do abuso sexual infantil. Inicialmente concebido como um acontecimento real, dentro da perspectiva denominada "teoria da sedução" - na qual o abuso sexual cometido pelo adulto contra a criança seria determinante para as afecções neuróticas -, Freud posteriormente abandona esta perspectiva para aceder a uma teorização sobre a fantasia. Assim, o trauma passa a ser concebido como um excesso de excitação subjetivamente insuportável, lá onde a experiência libidinal extrapola as condições de compreensão do aparelho psíquico. É justamente o caráter quantitativo que acompanha a ideia de excesso traumático que leva Freud a justificá-lo em termos da economia libidinal (Freud, 1917/2014). A vivência traumática se torna intolerável para o repertório representacional de que o sujeito dispõe; no momento em que ocorre, esta vivência do excesso não é passível de uma experiência no campo do sentido, permanecendo na vida psíquica como uma "presença adiada" (uma criança sob abuso não tem condições psíquicas de entender o que lhe acontece, por exemplo) -, ou seja, uma vivência intervalar no que se refere aos requisitos próprios do processo de significação. Será somente quando for possível conferir significado e sentido à experiência do excesso - em termos freudianos, quando for possível representá-la - que a condição traumática rigorosamente se instalará (lá onde tardiamente a criança é capaz de reconhecer retroativamente o que enfim lhe ocorrera na situação do abuso). É por isso que, para compreender a condição traumática no que ela tem de transformacional desde esse segundo momento que se sobrepõe ao primeiro, Freud necessita de um esquema com ao menos duas cenas em dois tempos distintos para a sua teorização do trauma: é lá quando há recursos psíquicos para a subjetivação do trauma que ele se instala, a posteriori (Nachträglichkeit)2.

Obviamente, o abuso sexual infantil não é a única figura do trauma que Freud tem em vista. É deveras conhecida sua experiência com as neuroses traumáticas em decorrência da guerra. $\mathrm{O}$ choque abrupto pelo qual passaram os soldados na Primeira Guerra Mundial, das neuroses de guerra. Entre 1915 (Freud, 1915/2010) e 1920 (Freud, 1920/2010), Freud reconfigurará seu programa metapsicológico, propondo ao fim deste período sua segunda teoria pulsional, pautada pela dualidade entre pulsão de vida e pulsão de morte. Esta nova concepção do conflito pulsional possibilitou ao pai da psicanálise compreender como

\footnotetext{
${ }^{2}$ Um roteiro detalhado deste percurso no pensamento freudiano pode ser encontrado em Celes, 1999.
} 
o sonho traumático dos soldados de guerra insistia em uma repetição surpreendentemente incapaz de dar ensejo à função onírica de elaboração. É como se, ao retificar em partes o postulado de sua Interpretação dos sonhos em que o sonho realiza um desejo e, não obstante, ao desigualar o trauma do protótipo do abuso sexual tal como concebido até então, nem mesmo a condição de significação $a$ posteriori fosse possível, permanecendo o sujeito traumatizado em um estado de repetição contínua, na eternização do intervalo entre os dois tempos do trauma. Logo, é justamente porque Freud não se restringiu ao problema do abuso sexual infantil (posto que soube extrair dele as principais consequências teóricas e clínicas) que lhe foi possível expandir o horizonte da condição traumática mantendo a temporalidade que lhe é própria, mas destinando-a ao campo do que pode permanecer no campo da irrepresentabilidade (na ordem das pulsões de morte) e do que resiste à elaboração psíquica. Ou seja, com a segunda teoria pulsional freudiana, a dinâmica das pulsões é inteiramente reformulada desde uma perspectiva no qual a pulsão de vida é representável e a pulsão de morte é irrepresentável. Se a pulsão de morte passa a designar a partir de 1920 as experiências subjetivas que se dissociam da dimensão da representação em um vórtice que tende a um retorno ao estado inorgânico livre do conflito, é preciso que haja uma maneira de elaboração (e também reparação) do irrepresentável.

Ora, se é verdade que Freud nunca recuou diante da pergunta: "Como então esquecer aquilo de que não dá pra não lembrar?", desde as suas primeiras impressões sobre o trauma sexual até as decisivas impressões sobre as neuroses de guerra e à segunda teoria pulsional, cria-se na tradição psicanalítica uma discussão a respeito do que se realiza e do que não se realiza em um percurso de análise. É acompanhando Freud que seu discípulo e analisando Sandor Ferenczi - certamente um dos autores mais brilhantes da história da psicanálise - dispõe ao longo de sua obra discussões muito versáteis, estabelecidas ao longo de toda a sua experiência intelectual, que se debruçam sobre a dimensão do trauma, suas implicações e consequências. O psicanalista húngaro pôde abrir outras perspectivas para a compreensão da condição traumática que levarão às últimas consequências a dimensão do não integrável ao psiquismo, sendo o trauma aquele elemento não metabolizável pelo sujeito no repertório representacional. Coube a ele descrever de que maneira a clivagem do Eu aparece como um esforço de sobrevivência psíquica. Dizendo de outro modo, a autotomia narcísica aparece como a descrição do processo de clivagem: analogamente à lagartixa que abandona sua própria cauda para sobreviver em uma situação de perigo, o Eu se dissocia dos elementos que o compõem para permanecer subsistindo. Ferenczi dirá: "Um novo Eu não pode ser formado a partir do Eu precedente, mas a partir de fragmentos, produtos mais ou menos elementares de decomposição deste último" (Ferenczi, 1932/1990, p. 227).

A experiência do trauma é aquela que pulveriza, fragmenta, estilhaça as condições integrativas da vida psíquica. A solução somática se apresenta no retorno da sensação física angustiante que acompanha a lembrança traumática. Para Ferenczi, a simbolização parte dos fenômenos do corpo, posto que este é a sede e o destino do símbolo (Ferenczi, 1913/2011), como na conhecida alusão à criança que se põe à frente do Rio Sena e se espanta dizendo "Nossa, quanto cuspe?". As possibilidades de simbolização do trauma passam pelo corpo, enquanto sede da experiência da angústia, sendo a própria relação entre o corpo e o símbolo determinante para os impasses e os encaminhamentos da vivência traumática no psiquismo. A angústia traumática sinaliza o medo da loucura (Ferenczi, 1934/2011): a clivagem constitui, portanto, uma defesa que, se não analisada, pode levar o sujeito ao que o psicanalista húngaro chamará de "progressão traumática", um estado constante de repetição dos mecanismos de fragmentação da vida psíquica.

Há ainda uma restituição da temática do acontecimento real do trauma em Ferenczi; ele não retorna à teoria da sedução, certamente, mas imprime em sua teorização do trauma a reatualização própria do acontecimento real do trauma na relação entre crianças e adultos, lida sob a chave de uma "confusão de línguas" entre eles em seu ponto último de teorização do trauma. Neste texto, Ferenczi versa sobre o fenômeno em que a língua da ternura da criança é atravessada pela língua da paixão ${ }^{3}$ do adulto. Nota-se aqui que não há uma recuperação simples e inadvertida do protótipo do abuso sexual infantil para todo e qualquer pensamento sobre o trauma em psicanálise. Há sobretudo uma forma de alçar a dissimetria

${ }^{3}$ Paixão aqui compreendida enquanto excesso. A este respeito, conferir Osmo e Kupermann (2012). 
da experiência traumática definitivamente para além da realidade material ordinária (a ocorrência real do abuso) em direção à realidade psíquica, na materialidade própria do campo da linguagem. Dizendo de outro modo: Confusão de língua entre os adultos e a criança (Ferenczi, 1933/2011) é provavelmente o texto que satisfatoriamente "quita a dívida" do protótipo do abuso sexual infantil na concepção do trauma em psicanálise para, enfim no campo da linguagem, pensa-lo em sua dimensão intersubjetiva - tão necessária para as inquietações próprias à clínica do trauma. Não será por outro motivo que este autor é hoje considerado como "pai" da atenção conferida pela psicanálise às dimensões da intersubjetividade; graças às suas inflexões teóricas, a partir de Ferenczi tornou-se imprescindível a necessidade de tornar a técnica psicanalítica mais "elástica".

Uma análise, portanto, estaria a serviço de uma tentativa de reunificação dos fragmentos clivados do eu. A aposta nesta possível reunificação em uma síntese psíquica é assegurada pela simbolização partilhada na experiência analítica, que depende fundamentalmente da disposição do analista à empatia, ao tato e ao sentir-com (Einfuhlung). A importância da empatia reside fundamentalmente no fato de que a análise deve não se esgotar na repetição eterna da experiência traumática. Logo, será a técnica psicanalítica que será interpelada a partir dos impasses de uma paradoxalidade radical: se a repetição, cujo motor desde Freud é a pulsão de morte, é convocada a se reatualizar na situação transferencial, então como a transferência ela mesma não estará fadada a um giro infinito e indissolúvel em torno do impossível simbolizar, do impossível integrar? Torok afirma: "se seus tormentos não relaxam, apesar dos sofrimentos causados, é que neles revive o desejo com relação ao objeto e que, neles, ele se satisfaz" (Torok, 1995, p. 231); saciado em uma "regressão alucinatória", o encontro entre o desejo e o objeto pode estar fadado à repetição. Ora, o antídoto contra este curto-circuito da repetição do trauma na transferência é a presença empática do analista: é a capacidade de sentir-com que se apresenta como determinante para garantir a sobrevivência de um psiquismo estilhaçado. Ferenczi, em sua Questão de fim de análise, não deixa de ser otimista: não deveria, ao fim e ao cabo de um processo de análise, haver restos no fim da análise. Freud, por sua vez, em Análise terminável e interminável, rende homenagem ao pioneirismo de Ferenczi de introdu- zir a questão do fim da análise na história da psicanálise, mas o faz com alguma reserva. Não seria justamente esta finalidade da cura analítica proposta por Ferenczi uma espécie de "protoconceituação" da noção de reparação ou, ao menos, a primeira grande aposta em sua positivação? Aquela que consagrará definitivamente o conceito de reparação em psicanálise será, como já anunciamos anteriormente, sua analisante, Melanie Klein. A ela nos caberá perguntar: o que repara, afinal, uma análise?

\section{Reparação e sublimação: Melanie Klein e a tradição inglesa da psicanálise}

Ao longo de três décadas de experiência intelectual e clínica, Melanie Klein foi a responsável por tornar factível a clínica psicanalítica com crianças. Coube a ela, analisada por Ferenczi e encorajada por ele a prosseguir nas investigações clínicas do tratamento de crianças, desbravar este campo fértil e promover as técnicas adequadas para tal. Antes mesmo de nos debruçarmos sobre a especificidade do conceito de reparação na obra kleiniana, será preciso apresenta-la ao lado de uma noção que lhe é suplementar, que é a de restauração.

Na segunda parte de A Psicanálise de crianças (Klein, 1932/1997), restaurar e reparar acompanha o movimento da criança em direção ao seio materno em termos de ataques sádicos e destrutivos. Levada pela ansiedade que caracteriza a experiência subjetiva do bebê pela exigência implacável de dar destino à pulsão de morte, inicia-se o intrincado processo de constituição das relações objetais: "podemos talvez dizer que a relação do sujeito com a realidade externa exprimiria, em última instância, sua constituição pulsional agressiva" (Caropreso, 2015, p. 395). A agressividade gera um curto-circuito em que a ameaça de destruição do objeto se reverte em ameaça de autodestruição, caracterizando o tom persecutório da fantasia primitiva da criança. Segundo ela, a possibilidade de a criança restaurar o objeto danificado ou retalhado em sua fantasia destrutiva é aquilo que poderá oferecer uma relação mais integrada com o objeto. Ao longo da década de 1930 e nos anos seguintes, em que a psicanalista receberia em seu consultório casos em que o comprometimento psíquico era crescentemente mais grave, ela centralizará em sua teorização o processo de reparação. Em textos centrais para a compreensão dos desenvolvimentos do pensamento kleiniano como Uma contribuição à psicogênese dos estados maníaco-depressivos de 1935 (Klein, 1935/1996) e 
O luto e suas relações com os estados maníaco-depressivos de 1940 (Klein, 1940/1996), o conceito de reparação passará a se tornar proeminente para sinalar "o reconhecimento de responsabilidade pelas depredações da agressão fantasiada: o portão para o mundo das relações interpessoais maduras" (Dews, 2008, p. 26). É neste sentido que reparar se coloca ao lado do amar e do (se) culpar. Efetua-se assim a passagem da "lei da selva" característica do primeiro semestre de vida do bebê para a "lei da cultura e do social" (Cintra, \& Figueiredo, 2004): a atividade reparatória busca integrar aquilo que ela crê estar ainda despedaçado por conta de seus ataques destrutivos iniciais contra o seio materno fragmentado - objeto originário a que todo e qualquer processo de reparação está necessariamente dirigido. Por um lado, a reparação decorre da restauração no que tange o processo de constituição de uma experiência de constância de objeto; enquanto progressivamente o bebê se exonera do estado de controle onipotente próprio da posição ${ }^{4}$ esquizoparanoide, nas relações objetais totais ${ }^{5}$ ele cria condições para vir a assumir a condição própria da posição depressiva, em que seio bom e seio mau se tornam, na verdade, um objeto integrado, capaz de ser simultaneamente amado e odiado de modo suportável. Por outro, a reparação é condição para a subjetivação da experiência de culpa, uma vez que a expectativa persecutória de retaliação ou ataque sádico do objeto destruído não se confirma; sem a chancela desta espécie de vingança do objeto que acossava o bebê nos períodos rudimentares da vida, a conquista da distinção entre fantasia e realidade em termos de equilíbrio subjetivo entre mundo interno e mundo externo imprime ao processo reparatório um estado madurado de integração.

Esta incursão na obra kleiniana se faz necessária para que se possa inferir uma diferença sensível entre restauração e reparação na obra da psicanalista. Não seria arriscado deduzir que a psicanalista, vienense de nascimento, tinha conhecimento da sutil dessemelhança que evocamos inicialmente entre
Wiederherstellung e Wiedergutmachung em sua língua mãe. É deste modo que a condição de "fazer de novo o bom" na reparação é que a criança esteja na posição depressiva, na qual a criança após os 6 meses de idade configura um tipo particular de melancolia - não equivalente à definida por Freud em Luto $e$ melancolia (Freud, 1917/2010), mas uma melancolia "em status nascendi" (Klein, 1940/1996, p. 388). Haveria, deste modo, um elemento obsessivo ${ }^{6}$ no processo reparatório, uma vez posta "a necessidade de controlar outras pessoas [...] até certo ponto explicada por um impulso defletido de controlar partes do self" (Klein, 1946/1991, p. 32). Ao mesmo tempo em que designa um mecanismo de defesa próprio da posição depressiva, a reparação institui a capacidade criativa própria do procedimento artístico. Não será por acaso que, em textos tardios como Inveja e gratidão, lemos que "a criatividade é a causa mais profunda da inveja" (Klein, 1957/1991, p. 234): é a maneira que a psicanalista encontra para reafirmar, à maneira de Freud, que mesmo os processos criativos são impelidos pela pulsão de morte. Não obstante, se aquilo que ela chama de inveja primária implicaria uma fantasia sádica vivenciada como profundamente perturbadora, na experiência tardia da reparação será a gratidão que se apresentará como o seu correlato necessário, no qual a capacidade de amar é motivada pelas pulsões de vida; sem que a inveja da criatividade impeça mais a própria criação, o sentimento de gratidão configura o estado último de permanência e sobrevivência do objeto bom na vida psíquica.

Dito isso, vale ao menos apontar que o conceito kleiniano de reparação ecoará em autores como Wilfred Bion e Donald Winnicott. Ainda que faça pouco uso da recuperação do conceito de reparação kleiniano (Junqueira Filho, 2014), Bion promove o conceito de at-one-ment (redenção, reconciliação, concórdia, também traduzido por reparação) em seu livro clássico Atenção e interpretação (Bion, 1991). A raiz da palavra remente à religião: atonement é reparação no sentido de expiação,

\footnotetext{
4 "Posição" não se confunde com a estratégia freudiana de definição de fases do desenvolvimento psicossexual. Para Freud, a organização libidinal se dá em torno da eleição de diferentes zonas erógenas na infância para a obtenção de prazer e satisfação das pulsões sexuais. As estratégias da criança para a obtenção do prazer se transformam de acordo com as zonas erógenas priorizadas, que por sua vez determinam as fases pelas quais ela passa - oral, sádico-anal, fálica e genital. Já Melanie Klein define duas posições no curso da constituição subjetiva: a posição esquizoparanoide (Klein, 1946/1991) - do nascimento até seis meses em média - e a depressiva - após seis meses de idade; sem encerrá-las em um "etapismo" em que cada estágio se obsoletaria pelo simples surgimento do estágio seguinte, a estratégia kleiniana abre espaço para pensar a posição enquanto matriz do funcionamento psíquico, interessando mais as modalidades de relação de objeto do que a compreensão da via direta de satisfação pulsional pela fase em que a criança se encontra.

${ }^{5} \mathrm{~A}$ distinção entre objeto parcial e objeto total é uma das principais contribuições à psicanálise de Karl Abraham, que viria a ser o segundo analista de Melanie Klein. Conferir Mezan, 1999.

${ }^{6}$ A respeito da concepção kleiniana de neurose obsessiva, conferir Klipan e Mello Neto (2012).
} 
sacrifício, com vistas à compensação. O jogo de palavra que permite a Bion conceber at-one-ment - termo de difícil tradução: unificação ou unicidade, mas também "com-união", "ser-um-com", "estar em uníssono com" (Bianchedi, \& Bianchedi, 1998, p. 193) - indica uma reconciliação para consigo mesmo por meio da capacidade de rêverie, conceito-chave que destaca e ilumina a relação de objeto, indicando ideias como tolerância ou harmonia.

Winnicott por sua vez, rende homenagem ao conceito kleineano de reparação em $A$ reparação em função da defesa materna contra a depressão, de 1958 (Winnicott, 1958/2000), e, posteriormente, revisita-o em Agressão, culpa e reparação, de 1960 (Winnicott, 1960/1999). Já antes destes, o psicanalista inglês toma distância do kleinismo para desenvolver um pensamento original, especialmente a partir da publicação de Objetos transicionais e fenômenos transicionais, em 1951 (Winnicott, 1951/2000). É a partir deste texto que o autor inglês coloca a questão da transicionalidade, estranha ao kleinismo clássico, cujo objetivo principal é o de propiciar, por meio de um complexo processo de subjetivação do par presença-ausência materna, um ambiente facilitador, um espaço potencial criativo para as relações do sujeito com o mundo. $\mathrm{O}$ objetivo do tratamento psicanalítico consistiria assim na restituição da confiabilidade no ambiente, que aqui se inscreve como um espaço intermediário da experiência entre sujeito e objeto. O estatuto intersubjetivo da transicionalidade permite que o trauma seja reconciliado com o largo espectro compreendido entre os polos da dependência e da independência subjetiva, nuançado pelas ideias de dependência absoluta e dependência relativa. Em síntese, para Winnicott, "o trauma é um fracasso relativo à dependência” (Winnicott, 1965/1994, p. 113). O que acompanha assim a experiência traumática é o que ele denomina de medo do colapso: "o medo clínico do colapso é o medo de um colapso que já foi experienciado" (Winnicott, 1974/1994, p. 72).

A significativa transformação que sofre o conceito de reparação em Winnicott refere-se ao que ele chama de função do paradoxo. Há uma reticência razoavelmente maior do autor quando comparada à gratidão kleiniana quanto à possibilidade de integração total do objeto; por mais que o programa clínico winnicottiano seja pautado pela ideia da regressão à dependência para a restituição das falhas ambientais, o paradoxo na cons- tituição subjetiva é encaminhado no processo analítico de modo a ser tolerado, suficientemente suportado, mas não solucionado, resolvido ou dissolvido.

Obviamente, cada autor do pós-kleinismo mereceria uma exposição de conceitos mais profunda. Em suma, há uma linha (um tanto tortuosa, por vezes descontínua, mas verificável) da história da psicanálise $^{7}$, que se estende de Melanie Klein a Bion eWinnicott, bordejando outros autores do chamado middlegroup (como Michael Balint e Ronald Fairbain), até autores mais contemporâneos como Thomas Ogden, Christopher Bollas e outros. Mas, na evidente impossibilidade de fazer isso ao menos agora, cabe retomar nosso objetivo para já afirmar que na conceitografia kleineana (e na tradição que esta instala no pós-kleinismo) o conceito de reparação descende não do conceito de trauma, como se poderia supor inadvertidamente, mas sim é formulado a serviço do reposicionamento do conceito psicanalítico de sublimação. Reparação, neste sentido, caminha lado a lado na conceitografia kleineana com a ideia de gratidão, postas as duas no horizonte da cura psicanalítica enquanto competência de ampliação do psiquismo no que diz respeito à capacidade de suportar a angústia e exercer a criatividade em sua forma sublimada. Este aspecto, para os nossos fins, é central.

É possível afirmar deste modo que, ainda que consagrado por Melanie Klein, o conceito de reparação para esta autora nos informa menos a respeito da herança psicanalítica do conceito de trauma oriundo de Freud e Ferenczi - e, portanto, menos sobre a reparação que visa uma cura para a condição traumática - do que parecem sugerir os próprios autores do pós-kleinismo, Winnicott em destaque. No entanto, aquilo que aqui foi chamado de reticência em relação à reparação não foi alçado ao seu ponto mais radical na experiência inglesa. Foi preciso atravessar o Canal da Mancha para que a desconfiança crítica em relação à reparação pudesse se instalar na história da psicanálise em termos de discussão clínica e teórica, para enfim informar sobre a sua dimensão ética e política.

\section{Lacan, o objeto a e a ética da psicanálise: que clínica para uma irreparabilidade inexorável?}

Controverso, de originalidade ímpar, Jacques Lacan é autor indispensável e imprescindível em qual-

\footnotetext{
${ }^{7}$ Uma apresentação coesa sobre o pós-freudismo relacionando a matriz inglesa com o cenário psicanalítico do pós-guerra pode ser lida em Dunker, 2006a. Para uma análise mais demorada, recomenda-se o supracitado Mezan, 2014.
} 
quer discussão que recupere os debates mais relevantes da história da psicanálise. Sua formação em psiquiatra marcaria desde o início a distinção de sua experiência intelectual: no caso do psicanalista francês, não estava na gênese de seus trabalhos de escuta a clínica com crianças, mas a clínica das psicoses - em especial, a paranoia (Lacan, 1932/1987). Isso não impedirá Lacan de ser em vida um "diagnosticador do presente", para usar uma expressão de Michel Foucault. Colocando-se na dianteira das discussões sobre a psicanálise de seu tempo, este leitor ávido dos principais periódicos de psicanálise de então (e, talvez, até hoje), principalmente do International journal of psychoanalysis, mas também do The Psychoanalytic quarterly, da Revue française de psychanalyse e de tantos outros, Lacan esteve sempre apoiado em uma série de autores, repercutindo criticamente seus pressupostos, comentando seus casos clínicos, discutindo e dedicando lições de seus seminários àqueles que criticava. O fôlego largo de suas estratégias argumentativas se deve a isso e necessariamente exige um caminho de reconstrução. Fala-se aqui em reconstrução porque o psicanalista francês era notadamente avesso a "revisões" da obra freudiana: a ele interessava mais o "retorno a Freud" e, conforme suas próprias palavras, dele se fará arauto. Com sua paradoxal "ortodoxia renovada", ele levará ao pé da letra freudiana as condições de suas possíveis releituras e de seus próprios reposicionamentos. A "revisão", portanto, era para ele uma estratégia de esquecimento proposital do sentido da experiência freudiana e seu motor. Assim, é possível entender por que o a-historicismo, segundo ele, estava na América do Norte, mais precisamente, nos Estados Unidos. Texto exemplar é A coisa freudiana, de 1955: ao mesmo tempo em que criticava o neofreudismo culturalista de Karen Horney, criticava também uma preocupação hipostasiada pela teoria das relações objetais kleinianas e pós-kleinianas sobre "o pré-verbal, o gesto e a mímica, o tom, a ária da canção, o humor e o con-ta-to a-fe-ti-vo" (Lacan, 1955/1998, p. 414).

Posto isso, cabe aqui apenas indicar que a perspectiva do objeto perdido inaugura uma real diferença entre Lacan e os psicanalistas das relações objetais, sendo isso o mínimo suficiente para a nossa discussão a respeito do conceito de reparação. Como bem resume Chatelard,

Lacan, em seu ensino, ressalta que só se pode conceber o objeto se ele for apreendido sob a modalidade de sua falta, o que o inscreve fundamentalmente como objeto perdido; é por causa de sua perda que podemos falar de objeto. Seu estatuto é fundado retroativamente sobre o objeto a (Chatelard, 2005, p. 199).

Não é por acaso que, em sua ontologia negativa, o psicanalista francês pôde sublinhar ainda mais o caráter da falta, radicalmente estabelecida, pela insustentabilidade de qualquer proposta clínica de restituí-la, restaurá-la ou mesmo repará-la. Ou seja, Lacan recusa radicalmente um programa clínico que patine indefinidamente nas promessas nunca cumpridas da completude e da plenitude, de unificação de um suposto objeto dilacerado: a falta é condição implacável com a qual o sujeito terá que lidar pelo resto da vida, não sendo nunca e de nenhum modo tamponável. Assim sendo, o objeto faltante é uma espécie de pressuposto para o suporte da pulsão, esvaziado de sentido em si mesmo, a serviço da promoção do curto-circuito desejante. $\mathrm{Na}$ tradição lacaniana está mais em jogo a possibilidade de ler a relação de objeto desde a castração simbólica, ou seja, aquela que instaura a falta fundante, do que desde a frustração, imaginária, que pressupõe a possibilidade de completude alienada, ou mesmo a privação cuja natureza é real, o "furo", segundo a conceitografia lacaniana (Lacan, 1956-57/1995).

Logo, existe todo um programa clínico pautado nas dimensões dos registros do Real, Simbólico e Imaginário, que se entrelaçam nas perspectivas nuançadas da concepção lacaniana de transferência e incutem a ideia da falta inerente ao objeto nestes registros -cada qual referido a uma espécie de falta: a frustração, a castração e a privação. O modelo "estrutural-pulsional” de que fala Mezan se apresenta na ideia de que o alvo da pulsão é a negação do objeto (Safatle, 2006). Lacan dirá: "se Freud nos faz esta observação de que o objeto na pulsão não tem nenhuma importância, é provavelmente porque o seio deve ser revisado por inteiro quanto à sua função de objeto" (Lacan, 1964/1995, p. 160); ou seja, a ele interessa menos o objeto em sua materialidade ordinária, mas sim a sua função, que é a de ser suporte para a circulação e causação do desejo em sua rotatividade.

Sendo deste modo o desejo fundado na falta, a reparação do seio primevo despedaçado pelas injunções sádicas destrutivas tal como a concebia Melanie Klein seria uma proposição de completude imaginária, alienada por definição, impossível de se realizar. 
Um engodo, portanto: não haveria assim uma suplantação da falta; pelo contrário, há uma radicalização do confronto com a falta fundante que se apresenta como projeto clínico fundamental para Lacan. O objeto por excelência, segundo Lacan, é o chamado objeto a, causa do desejo. $\mathrm{O}$ objeto a é o resto que escapa à significação fálica; ele cria um curto-circuito no campo do desejo lá onde ele se apresenta como o objeto perdido desde sempre. Pois é pela função de objeto que o analista se posiciona em uma análise: é desde esta posição que ele faz operar uma análise. Indo além, na proposição dos quatro discursos, o objeto a ocupa a posição de agente no discurso do analista; é por "não pretender nenhuma solução" (Lacan, 1969-70/1992, p. 66), por não se permitir ser conduzida pelas imperícias do furor curandis, por não antecipar seu expediente segundo tal ou qual cartilha técnica do proceder analítico, que a análise leva a cabo sua função de tratamento. Logo, não seria arriscado dizer que a psicanálise, segundo Lacan, comporta algo da ordem da irreparabilidade do objeto: há de se criar uma nova relação com o desejo, despida dos anseios do "fazer-Um", para que, se ainda quisermos falar em reparação, que esta seja substancialmente motivada pelo desejo, e não que tenha em suas pretensões de cura uma ortopedia do Eu. Não obstante, como adverte Dunker,

tal conclusão não é exclusiva nem original em Lacan; já a psicanálise do eu, com uma versão sociológica da realidade, Winnicott, com uma revisão própria da "realidade da ilusão", e Klein, com sua teoria da "realidade das relações de objeto" (interna e externa), conduziram-se, teoricamente, de maneira semelhante. No fundo, são todas elas concepções que giram em torno da realidade precária do objeto (Dunker, 2007, p. 237).

Aqui já parece inegável que o ponto crítico radical quanto à colocação da reparação no horizonte de cura se deve ao lacanismo. Ainda que se possa guardar mais afinidade com a escola francesa, como é o caso deste que aqui escreve, não se deve fazer aqui, como é de costume em tantos espaços lacanianos ortodoxos, da conjectura do objeto uma profissão de fé antikleineana (ou anti-inglesa), tecendo juízo de valores sobre qual escola deve se sobrepujar em relação à outra - declino com absoluta segurança o convite ao juízo de valores, pois não é da velha e inócua "briga entre escolas" que se trata aqui. Ratificando os propósitos do presente artigo, pode-se minimamente inferir que a desconfiança e a hesitação de Lacan em relação a um programa clínico que prometa reparações plenas serve como uma advertência de ordem ética. Pois as consequências de se pensar a reparação na finalidade da cura psicanalítica não como um projeto adaptacionista, mas sim (e sobretudo) desalienante, inclui o desafio ético de não recair na tentação do Bem, que só conduz ao Pior (Koltai, 2002). Não será por outro motivo que a heroína da ética lacanina é Antígona. Filha do casamento incestuoso entre Édipo e Jocasta, na tragédia de Sófocles, Antígona é a representante do desejo levado às últimas consequências, na medida em que, ao tentar sepultar o cadáver do irmão, cujo corpo em decomposição é abandonado à mesma animalidade dos detritívoros que o devoram, indigno aos olhos da Lei de Creonte seu tio, acaba presa e enterrada viva. Antígona para Lacan é "braba - Ela é omos. Traduz-se isso como se pode, por inflexível. Quer dizer literalmente algo de não civilizado, de cru. [...]" (Lacan, 1959-60/1988, p. 319). O que está no centro do drama de Antígona é a Até ('A $\tau$ ), que na tragédia grega, que designa categorias múltiplas como a "desgraça", a "fatalidade", a "ruína", mas também a "cegueira da razão", a "insensatez". Cabe a longa citação:

Não há ninguém para assumir o crime e a validade do crime senão Antígona. Entre os dois, Antígona escolhe ser pura e simplesmente a guardiã do ser criminoso como tal. As coisas certamente poderiam ter tido um término se o corpo social tivesse aceitado perdoar, esquecer e cobrir tudo com as mesmas honras funerárias. É na medida em que a comunidade se recusa a isso que Antígona deve fazer o sacrifício de seu ser para a manutenção desse ser essencial que é a Até familiar - motivo, eixo verdadeiro, em torno do qual gira toda essa tragédia. Antígona perpetua, eterniza, imortaliza essa Até (Lacan, 1959-60/1988, p. 342).

Aqui a leitura lacaniana da tragédia de Antígona, cuja ética se fundamenta no não ceder do desejo lá onde este exige do sujeito a violação e transposição dos limites da Lei, parece encontrar a nossa temática da demanda por reconhecimento dos crimes perpetrados pelo Estado. Não é raro que os pacientes que procuram a reparação psíquica se encontrem em um estado de luto interrompido em seu curso esperado, cuja incapacidade de enterrar seus mortos esteja chancelada pela ausência sistemática do reconhecimento por parte 
do Estado. Ao restituir ao resto que não se inscreve na simbolização possível o lugar que lhe coube na devida herança freudiana, o psicanalista francês nos deixa a lição de que o ato ético é, em última instância, da ordem do irreparável. No entanto, irreparável não é o mesmo que impossível. Lacan, ele mesmo costumava dizer as melhores compreensões sobre a dimensão do impossível não se dão ao tomá-las pela negação que lhe é própria. Logo, compreender o que é possível respeitando a inexorabilidade do impossível reparar nos leva à discussão sobre a inscrição do acontecimento na rede de reconhecimento socialmente partilhada a que podemos chamar História.

\section{Permeabilidades da História ao caso: o testemunho enquanto combate ao revisionismo}

Parte-se aqui do pressuposto de que a historiografia da psicanálise deve se haver com a permeabilidade ao caso clínico enquanto um acontecimento singular. Há uma dimensão na qual a reunião de casos faz arquivo, justamente por poder potencialmente produzir verdades desde sua permanência e consolidação na cultura e na sociedade por uma política de memória. Ora, é esta a situação que tensiona, de um lado, aquilo que é próprio do exercício clínico, cujas bases residem na possibilidade de o paciente presentificar uma experiência passada - no tempo ulterior por definição do trauma em sua radical singularidade -, a fim de abrir, pela fala e pela palavra, novas formas de significação da experiência; e, de outro lado, aquilo que é próprio da história, que, desafiada pela experiência singular, deve se prestar a contínuos reposicionamentos e transformações diante dos acontecidos relatados. A história a longo prazo é interpelada pelos acontecimentos; são estes que podem de fato remodelar a compreensão geral de como nos tornamos o que hoje somos. Logo, "o trabalho de exumação de arquivos capaz de conceder privilégio à dimensão do acontecimento tem por objetivo possibilitar uma história com sujeitos falantes" (Lima, 2015, p. 115). Uma história de violações sistemáticas de direitos humanos, como a que ocorreu em nosso país, acaba por se tornar o solo do silêncio de nossa história não contada. Por mais contra intuitivo que possa parecer a princípio demandar tamanha responsabilidade das terapêuticas "psi" (em especial as de orientação psicanalítica, como é o caso das Clínicas do Testemunho), a aposta é mantida porque, muito longe de se redu- zir à privatização do sofrimento psíquico, elas estão no cerne da possibilidade de produzir condições de escuta de um sofrimento que não é chancelado ou legitimado enquanto tal no campo social. Ou seja,

o desmentido do fato real [...] inviabiliza a introjeção, a inscrição psíquica de todo evento traumático, restando somente para o sujeito ferido uma vivência sensorial, inacessível à memória e à palavra, porém existente. $\mathrm{O}$ desmentido, que impede a representação do acontecido, é a causa primordial para que o trauma se torne desestruturante, atenta contra o eu do sujeito, colocando em questão o jogo das identificações (Uchitel, 2001, p. 87).

Ou seja, aquilo que permanece como desmentido (Verleugnung) e que não se inscreve simbolicamente em um sistema representacional por meio do qual os indivíduos de uma determinada sociedade podem se fazer reconhecer uns pelos outros retorna sistematicamente como sintoma, não apenas no corpo e no psiquismo individual, mas também no sofrimento compartilhado de uma história denegada.

Há algumas passagens que precisam ser trabalhadas para a formação deste arquivo. Uma primeira passagem fundamental é a da escuta, incumbência propriamente clínica do psicanalista, para a escrita, função dramática na qual, como afirma o psicanalista André Green, "qualquer que seja ele [o objetivo], o autor analista está diante da folha em branco" (Green, 1992, p. 168). A escrita, outro conceito nobre em psicanálise, é compreendida aqui como uma tradução narrativa à luz da teoria de uma determinada experiência de atendimento que se deu em um número de sessões dispostas ao longo dos anos. Por conseguinte, essa escrita se transformará em relato de caso, capaz de expor os avanços ocorridos durante o tratamento; as diversas escritas de caso, no plural, serializadas e sequencializadas, dão origem a um acervo ou um catálogo, reunindo assim um trabalho comunitário à disposição pública de quem vier a consultá-lo em pesquisas universitárias, exercícios de reflexão clínica e formação de políticas públicas de saúde, para promover o avanço qualitativo de uma práxis. Portanto, do curso da escuta à constituição de um arquivo sensível que se anseie ou que se almeje patrimônio público, há uma apreciação que se dá graças a um processo minucioso de elaboração, no qual a experiência possa vir a ser posteriormente replicada em instâncias diversas. 
No horizonte destas instâncias, deve-se ter permanentemente em vista a criação de políticas públicas em saúde mental que sejam apropriadas para cumprir e executar esse ofício. Penso assim que a composição de tal arquivo sensível é uma das tarefas fundamentais do exame a ser realizado pelas Clínicas do Testemunho nesse período atual - algo próximo dos Livros dos votos da Comissão de Anistia, exemplo bem-sucedido do que deve ser a montagem de um arquivo, compilando os processos jurídicos de retratação promovidas pelo Estado entremeados a um "mosaico de casos individuais" (Abrão, 2013, p. 18). Todavia, é preciso ir além e indagar como imprimir a tonalidade de testemunho analítico a um arquivo sucedâneo a este. Tal justificação só será possível se considerarmos que as ações de políticas reparatórias promovidas pelo Estado estão situadas em uma zona de compromissos entre urgências sociais, históricas, políticas e clínicas. Uma terapêutica capaz de promover uma reparação psíquica à altura do sofrimento que lhe é demandada deve ser um exercício ético não conivente com as práticas de tortura e de violações de direitos humanos constitucionais, como o é, por exemplo, o direito à palavra - que, não por acaso, é também instituinte última da regra fundamental da psicanálise, a chamada associação livre. Se é necessário manter o estado de liberdade indispensável para que o paciente diga o que lhe vier à cabeça e ressignifique sua trajetória de vida, essa liberdade não pode ser de outra ordem que não aquela garantida pela política. Ademais, não seria arriscado afirmar que, estando suspenso o direito político à palavra, o pilar ético fundamental da psicanálise se encontra ameaçado de extinção (Roudinesco, 1995).

É bem verdade que partimos aqui da tese de que o estado democrático de direito garante (de algum modo, mas nem em todos os casos) a sobrevivência da psicanálise - e isso é a própria história da psicanálise quem prova. Não obstante, só se pode falar em reparação psíquica na medida em que o que está em jogo no horizonte da cura psicanalítica é o inverso à adaptação do sujeito ao meio social. Em outras palavras, o compromisso mais substancial da política da escuta analítica é com a suspensão da perspectiva de ajuste dos desviantes à norma. Permanece assim o desafio de manter unidos o dever ético de alavancar a palavra testemunhal no interior do trabalho de escuta para além do espaço supostamente privado em que ela ocorre; ou seja, no expediente das Clínicas do
Testemunho, é indispensável fecundar a sua correlata instalação na pólis. Sublinhar que "é a pressão social que alimenta a agenda da justiça transicional" (Abrão, 2011, p. 196) é sublinhar o modo pelo qual se informam mutuamente as Clínicas do Testemunho, com o seu louvável pioneirismo de reconstruir a posteriori os não ditos intersubjetivamente partilhados, e as exigências de uma Justiça de Transição, agenda política responsável pela consolidação decisiva de um estado democrático de direito.

Quero crer que a reforma das instituições perpetradoras das violações contra os direitos humanos, um dos pilares fundamentais da Justiça de Transição, também há de ser pautada pelo trabalho realizado pelas Clínicas do Testemunho. O desencontro entre a experiência do trauma vivenciado por aquele que sofreu violações fundamentais de seus direitos humanos e a chance de seu recolhimento em uma política que preze pelo direito à Memória, à Verdade e à Justiça se dá em uma complexa gramática do reconhecimento. Não ter a sua história reconhecida pelo Estado é entrar em permanente estado de repetição social da experiência traumática, que, do lado do sujeito, gira em torno de um sofrimento que não circula pelo Outro, e, do lado do Estado, mantém seus pontos cegos à custa de tantas outras vidas traumatizadas, sofridas e silenciadas, mesmo quando em continuidade com o nosso período democrático. Sabe-se que as estratégias de manutenção do silenciamento do sofrimento, seja individual ou coletivo, são mantidas ao longo da história de um país pela sua negação sistemática. O custo psíquico e social desta manutenção pode ser aproximado em um plano geral ao que Axel Honneth chama de "patologia do social": "Eu descrevo como patologias sociais as deficiências sociais no seio de uma sociedade, as quais não decorrem de uma violação dos princípios de justiça comumente aceitos, mas de danos às condições sociais de auto-realização individual" (Honneth, 2006, p. 35). É ainda nessa mesma esteira, ainda que com expedientes epistêmicos dessemelhantes, que se pode falar em "sintoma social": "se a tortura separa corpo e sujeito, cabe a nós assumir o lugar de sujeito em nome daqueles que já não têm direito a uma palavra que os represente" (Kehl, 2010, p. 131). Deve-se pensar assim na dupla função que exerce o trabalho propriamente psicanalítico do testemunhar: a dupla função, entre o público e o privado, de fazer valer o que há de comunitário no trauma singular bem como o que há de singular no trauma comunitário. Serão estas articulações 
que justificam a presença da escuta analítica na função do testemunhar: "a aniquilação do testemunho, da palavra em busca de si, que persegue a própria dor quando seria plausível fugir dela, não é a ausência do que dizer, mas não ter quem escute o que se pode dizer" (Endo, 2009, p. 55).

Longe de ser um procedimento de enunciação de caráter utilitário, fiel e restrito à ordem dos acontecimentos, o testemunho fratura o chão duro da história estritamente factual, traumatizando-o. O efeito que a palavra testemunhal provoca em termos de aparição da experiência subjetiva subjacente à violência política é de denúncia e de revelação. Contumaz por vocação, articulador de regimes de verdade por definição, o testemunho é capaz de exceder as catástrofes políticas por ser, ele próprio, a resistência ao aniquilamento lá onde estas se determinaram enquanto tal. A potência do dito do testemunho é, nesse sentido, verticalmente (no que se refere à experiência individual) e horizontalmente (os efeitos desta na história longitudinal) desobjetificante. Neste sentido, o testemunho propicia uma forma de combate ao revisionismo. Que ecoem aqui as palavras do filósofo alemão Walter Benjamin: "nunca houve um documento da cultura que não fosse também um documento da barbárie" (Benjamin, 1940/1987, p. 225). Superar os períodos de violência política da história do Brasil é mais do que aplainar as camadas sucessivas do devir temporal em uma ininterrupta retificação do passado até que nos esqueçamos dele ao fim do processo. Pelo contrário, a função do testemunho é, no limite, não admitir ser soterrado. Não há como apagar as manchas da violência, e penso que a estratégia não poderia ser essa, pois é a psicanálise mesma que ensina que a catástrofe carrega em si a ameaça de sua repetição. Para reconhecer a barbárie do passado para que ela não se reproduza no presente, é absolutamente imprescindível manter a olhos nus os vestígios do sangue espirrado pelas feridas traumáticas de nossa história, para, enfim, projetar futuros outros desde as nossas cicatrizes.

\section{Discussão: que reparação para a reparação psíquica?}

Essa brevíssima incursão nesses autores notáveis para a compreensão da ordem dos conceitos psicanalíticos lidos sob o ângulo da noção de reparação, atravessada pelas diferenças metapsicológicas e clínicas entre a tradição inglesa e a tradição francesa da psicanálise (que, verdade seja dita, por si só já dariam uma tese), serve-nos aqui para demonstrar a nobreza dos desdobramentos conceituais aqui envolvidos. Sem o objetivo de tê-los esgotado, mas pensando sobretudo em produções e desenvolvimentos futuros, parece-nos já possível concluir sobre quão ingênuo do ponto de vista do rigor epistemológico poderia ser sobrepor concepções de reparação tão díspares já dentro da própria psicanálise - o que dizer então de incluir, mais ainda, a proposta da reparação psíquica vinda de fora de seu campo conceitual de origem?

Para que haja efetivamente uma clínica psicanalítica voltada ao atendimento das vítimas de violência de Estado (de ontem e de hoje), é preciso informar ao Estado a conjuntura da discussão sobre reparação no campo psicanalítico. Nele - espero que a esta altura do texto isso esteja minimamente claro - não há uma posição consensual, nem mesmo entre os autores canônicos mais "semelhantes" entre si, sobre o que é reparação.

Não obstante, quisemos demonstrar como, desde Freud, quando se trata de clínica psicanalítica, o método deve ser interpelado pelo objeto. Ou seja, a psicanálise, longe de se encerrar em um mero dispositivo técnico replicável nas mais diversas situações clínicas, tem o mérito de se reinventar a partir da particularidade de uma experiência de escuta. Ela não é imune às demandas que lhe são impostas no campo social; pelo contrário, uma psicanálise que não se afeta por estas demandas, ou que se crê fora delas, não pode ser outra coisa que não a reprodução alienada de um suposto a-historicismo de sua práxis que não se confirma enquanto tal. Ora, penso que isso não se dá por acaso: há uma exigência deste tipo específico de experiência de escuta nas Clínicas do Testemunho que leva aqueles que se mostram disponíveis a pensá-las e problematizá-las à luz desta pauta.

Se parece claro que hoje há uma rede complexa de reconhecimento, que se estende do reconhecimento do outro (psicanalista) ao Outro (simbólico, estrutural, social, histórico), é preciso trabalhar para entender como, pela via contrária, tal reconhecimento retorna à psicanálise, com vistas à interpelação de sua práxis. Não caberia repetir o argumento datado de que a clínica da reparação psíquica enquanto clínica do trauma não deve se reduzir a uma clínica da interpretação. Temos ótimos exemplos em nossa literatura psicanalítica vigente sobre a reabilitação da interpretação para a clínica do trauma; Dunker (2006b), por exemplo, diferencia o trauma como desencontro do trauma como reencontro, expondo como uma clínica do trauma 
torna indispensável a tarefa interpretativa. Há nessa mesma literatura vigente uma série de desenvolvimentos a respeito do estabelecimento de diferenças entre uma "clínica do recalcamento" e uma "clínica da dissociação" (Gurfinkel, 2001), que pautaria diferentes programas clínicos na diferença que lhe é correlata, entre "ética do cuidado" e "ética da castração" (Souza, 1998).

Ora, sendo devidamente rigoroso, por mais didáticas e interessantes que possam ser, estas últimas distinções entre clínica do recalcamento e clínica da dissociação, ou entre ética do cuidado e ética da castração, costumam recair em caricaturizações profundamente inconvenientes. Parece-nos urgente sair do internalismo psicanalítico para compreender os efeitos de quando a psicanálise deve responder ao chamado do Estado por ser este próprio chamado uma convocação de ordem ética e política, ao passo em que também não há porque não pensar que o Estado também não deva ouvir o que a psicanálise tem a dizer sobre a violência de Estado. Isso exigirá uma boa vontade de ambas as partes que, no que tange à história da psicanálise, nem sempre houve.

\section{Conclusão: reparar o irreparável?}

Ora, dificilmente qualquer psicanalista, pela experiência de sua clínica, advogaria em favor de uma tese nominalista do conceito de reparação. Não há como não dimensionar o caráter transformacional pelo qual o psiquismo passa no processo reparatório. O problema é quando o reconhecimento do processo reparatório passa a ser traduzido em termos normativos ou adaptativos, cujo sofrimento individual passa a ser generalizado ou dissolvido em uma experiência coletiva, para não dizer do Pior que seria silenciá-lo. Advoga-se aqui que o antídoto contra tal tradução errática é resgatar o aspecto fundamental de perguntar de que objeto se trata na reparação promovida pelo processo da Justiça de Transição que se serve da psicanálise. Por exemplo, quando se quer implantar a possibilidade de que a violência de Estado não se repita, é preciso reconhecer as diferenças entre os violentados da época da ditadura e os que são hoje violentados pelos agentes do Estado. Quanto à natureza e função do objeto, é preciso ao menos indicar que deve-se ir com mais cautela quanto à ideia de continuidade entre "o Amarildo de hoje" e "o Rubens Paiva de ontem". Estamos falando do mesmo objeto? Por exemplo, não é comum que de um jovem negro e periférico, alvo primordial da violência de Estado promovida pela nossa Polícia Militar, carregue consigo uma cápsula de cianureto no bolso para não denunciar seus pares, para ter ao menos a opção de pôr fim à própria vida antes de revelar qualquer informação aos seus algozes. A tortura tem finalidade confessional nos dois casos? O desaparecimento cumpre qual finalidade? Que condições para se inscrever simbolicamente em um laço com seus pares tem o jovem negro periférico, de tal modo que consiga contemplar sua vulnerabilidade social?

Em que medida a nossa longa história de racismo, de exclusão dos negros da vida social e de criminalização da pobreza atravessa o processo de consolidação e sustentação da democracia hoje? Em termos psicanalíticos, poderíamos perguntar: que objeto aqui permanece sendo denegado?

Pois se há algo que possa fazer pender o irreparável em direção ao reparável, é o reconhecimento, aspecto crucial para o tratamento psíquico ou para uma cura social digna deste nome. Neste sentido, há, por fim, uma lição positiva que a noção psicanalítica de reparação oferece à nossa Justiça de Transição: a de sempre lembrar de perguntar, afinal, de que objeto se trata.

\section{Referências}

Abrão, P. (2011). A Lei da Anistia no Brasil: as alternativas para a verdade e a justiça. In K. M. Dotto, P. C. Endo, S. E. Sposito, \& T. C. Endo (Orgs.), Psicologia, violência e direitos humanos (pp. 176-197). São Paulo, SP: CRP-SP.

Abrão, P. (2013). Os votos da Comissão de Anistia: da reparação à memória e verdade. In M. J. H. \& V. Rotta (Orgs.), Livro dos votos da Comissão de Anistia: verdade e reparação aos perseguidos políticos no Brasil (pp. 18-19). Brasília, DF: Ministério da Justiça.

Abrão, P., \& Torelly, M. D. (2012). Mutações do conceito de anistia na justiça de transição brasileira: a terceira fase luta pela anistia. In C. Fico, M. P. Araujo, \& M. Grin (Orgs.), Violência na história: memória, trauma e reparação (pp. 177-197). Rio de Janeiro, RJ: Ponteio.

Benjamin, W. (1987) As teses sobre o conceito de história. In W. Benjamin, Obras escolhidas. Vol. 1. Magia e técnica, arte e política (pp. 222-232, Ensaios sobre literatura e história da cultura). São Paulo, SP: Brasiliense. (Trabalho original publicado em 1940). 
Bianchedi, M. \& Bianchedi, E. T. (1998). Da harmonia do escutar à melodia do interpretar: bi-escuta / bi-interpretação do instrumento psicanalítico. In L. C. U. Junqueira Filho (Org.), Silêncios e luzes: sobre a experiência psíquica do vazio e da forma (pp. 193-200). São Paulo, SP: Casa do Psicólogo.

Bion, W. (1991) Atenção e interpretação: o acesso científico à intuição em psicanálise e grupos. Rio de Janeiro, RJ: Imago. (Trabalho original publicado em 1970).

Caropreso, F. (2015). Pulsão de morte e experiências precoces em Freud e Melanie Klein. Revista de Filosofia Aurora, 27(40), 387-408. https:// doi.org/10.7213/aurora.27.040.AO07

Celes, L. A. (1999). Temporalidade do trauma: gênese mais estrutura no pensamento freudiano. Psicologia: Reflexão e Crítica, 12(3). http://dx.doi.org/10.1590/S0102-79721999000300007

Chatelard, D. S. (2005). O conceito de objeto na psicanálise: do fenômeno à escrita. Brasília, DF: UnB.

Cintra, E. M. U., \& Figueiredo, L. C. (2004). Melanie Klein: estilo e pensamento. São Paulo, SP: Escuta.

Dews, P. (2008). O problema do mal após Freud. In V., Safatle, \& R. Manzi (Orgs.), A filosofia após Freud (pp. 15-32). São Paulo, SP: Humanitas.

Dunker, C. I. L. (2006b). A função terapêutica do real: trauma, ato e fantasia. Pulsional Revista de Psicanálise, (186), 15-24. Recuperado em: http://www.editoraescuta.com.br/pulsional/186_03.pdf

Dunker, C. I. L. (2006a). Aspectos históricos da psicanálise pós-freudiana. In A. M. Jacó-Vilela, A. A. L. Ferreira, \& F. T. Portugal (Orgs.). História da psicologia: rumos e percursos (pp. 387-412). Rio de Janeiro, RJ: Nau.

Dunker, C. I. L. (2007). Ontologia negativa em psicanálise: entre ética e epistemologia. Discurso, 36, 212-239. Recuperado de https://www.revistas.usp.br/discurso/article/view/38078

Endo, P. (2009). A dor dos recomeços: luta pelo reconhecimento e pelo devir histórico no Brasil. Em: Revista Anistia - Política e Justiça de Transição, 2, 50-63. Recuperado de http://www.justica.gov.br/central-de-conteudo/ anistia/anexos/2010revistaanistia02.pdf

Ferenczi, S. (2011). Confusão delíngua entre os adultos e a criança. InS. Ferenczi, Obrascompletas(Vol.4,pp. 111-121). São Paulo, SP:WMF Martins Fontes. (Trabalho original publicado em 1933).

Ferenczi, S. (1990). Diário clínico. São Paulo, SP: Martins Fontes. (Trabalho original publicado em 1932).

Ferenczi, S. (2011). Ontogênese do símbolo. In S.Ferenczi, Obras completas (Vol. 2, pp. 115-118). São Paulo, SP: WMF Martins Fontes. (Trabalho original publicado em 1913).

Ferenczi, S. (2011). Reflexões sobre o trauma. In S. Ferenczi, Obras completas (Vol. 4, pp. 126-135). São Paulo, SP: WMF Martins Fontes. (Trabalho original publicado em 1934).

Freud, S. (2014). A fixação no trauma, o inconsciente. In S. Freud, Obras completas. Vol. 13: Conferências introdutórias à psicanálise (1916-1917) (pp. 364-380). São Paulo, SP: Companhia das Letras. (Trabalho original publicado em 1917).

Freud, S. (2010). Além do princípio do prazer. In S. Freud, Obras completas. Vol. 14: História de uma neurose infantil (“O Homem dos Lobos"), Além do Princípio do Prazer e outros textos (1917-1920) (pp. 161-239). São Paulo, SP: Companhia das Letras. (Trabalho original publicado em 1920).

Freud, S. (2010) Considerações atuais sobre a guerra e a morte. In S. Freud, Obras completas. Vol. 12: Introdução ao narcisismo, ensaios de metapsicologia e outros textos (1914-1916) (pp. 209-246). São Paulo, SP: Companhia das Letras. (Trabalho original publicado em 1915).

Freud, S. (2010). Luto e melancolia. In S. Freud, Obras completas. Vol. 12: Introdução ao narcisismo, ensaios de metapsicologia e outros textos (1914-1916) (pp. 170-194). São Paulo, SP: Companhia das Letras. (Trabalho original publicado em 1917)

Green, A. (1992). Transcrição da origem desconhecida: a escrita do psicanalista: crítica do testemunho. Revista Brasileira de Psicanálise, 26(1/2), 151-190.

Gurfinkel, D. (2001). Do sonho ao trauma : psicossoma e adicções. São Paulo, SP: Casa do Psicólogo.

Honneth, A. (2006). La société du Mépris: vers une nouvelle théorie critique. Paris: Editions La Découverte.

Junqueira Filho, L. C. U. (2014). Bion, epistemólogo. Jornal de Psicanálise, 47(86), 257-298. São Paulo, SP. Recuperado de http://pepsic.bvsalud.org/scielo.php?script=sci_arttext\&pid=S0103-58352014000100021 
Kehl, M. R. (2010). Tortura e sintoma social. In V. Safatle, \& E. Teles, O que resta da ditadura: a exceção brasileira (pp. 123-132). São Paulo, SP: Boitempo.

Klein, M. (1997). A psicanálise de crianças. Rio de Janeiro, RJ: Imago. (Trabalho original publicado em 1932).

Klein, M. (1991). Inveja e gratidão. In M. Klein, Inveja e gratidão e outros trabalhos (1946-1963) (pp. 205-267). Rio de Janeiro, RJ: Imago. (Trabalho original publicado em 1957).

Klein, M. (1991). Notas sobre alguns mecanismos esquizoides. In M. Klein, Inveja e gratidão e outros trabalhos (1946-1963) (pp. 17-43). Rio de Janeiro, RJ: Imago. (Trabalho original publicado em 1946).

Klein, M. (1996). O luto e suas relações com os estados maníaco-depressivos. In M. Klein, Amor, culpa e reparação e outros trabalhos (1921-1945) (pp. 385-412). Rio de Janeiro, RJ: Imago. (Trabalho original publicado em 1940).

Klein, M. (1996). Uma contribuição para a psicogênese dos estados maníaco-depressivos. In M. Klein, Amor, culpa e reparação e outros trabalhos (1921-1945) (pp. 301-329). Rio de Janeiro, RJ: Imago. (Trabalho original publicado em 1935).

Klipan, M .L., \& Mello Neto, G. A. R. (2012). A neurose obsessiva sob a ótica de Melanie Klein. Ágora (Rio J.), 15(2), 311-325. https://doi.org/10.1590/S1516-14982012000200008

Koltai, C. (2002). A tentação do bem: o caminho mais curto para o pior... Ágora (Rio J.), 5(1), 9-17. https://doi.org/10.1590/S1516-14982002000100001

Lacan, J. (1998). A coisa freudiana. In J. Lacan, Escritos (pp. 402-437). Rio de Janeiro, RJ: Jorge Zahar. (Trabalho original publicado em 1955)

Lacan, J. (1987). Da psicose paranoica em suas relações com a personalidade. Rio de Janeiro, RJ: Forense Universitária. (Trabalho original publicado em 1932).

Lacan, J. (1995). O seminário, livro 4: a relação de objeto. Rio de Janeiro, RJ: Jorge Zahar. (Trabalho original publicado em 1956-57).

Lacan, J. (1988). O seminário, livro 7: a ética da psicanálise. Rio de Janeiro, RJ: Jorge Zahar. (Trabalho original publicado em 1959-60).

Lacan, J. (1995). O Seminário, livro 11: os quatro conceitos fundamentais da psicanálise. Rio de Janeiro, RJ: Jorge Zahar. (Trabalho original publicado em 1964).

Lacan, J. (1992). O Seminário, livro 17: o avesso da psicanálise. Rio de Janeiro, RJ: Jorge Zahar. (Trabalho original publicado em 1969-70).

Lima, R. A. (2015). Por uma historiografia foucaultiana para a psicanálise: o poder como método. São Paulo, SP: Via Lettera.

Ludi, R. (2012). Reparations for Nazi victims in postwar Europe. New York, NY: Cambridge University Press.

Mezan, R. (1999). O inconsciente segundo Karl Abraham. Psicologia USP, 10(1), 55-95. https://doi.org/10.1590/ S0103-65641999000100004

Mezan, R. (2014). O tronco e os ramos: estudos de história da psicanálise. São Paulo, SP: Companhia das Letras.

Osmo, A. \& Kupermann, D. (2012). Confusão de línguas, trauma e hospitalidade em Sandor Ferenczi. I Psicologia em Estudo, 17(2), 329-339. https://doi.org/10.1590/S1413-73722012000200016

Roudinesco, E. (1995). Genealogias. Rio de Janeiro, RJ: Relume Dumará.

Safatle, V. (2006). A paixão do negativo: Lacan e a dialética. São Paulo, SP: Unesp.

Souza, O. (1998). A metapsicologia e as opções éticas dos psicanalistas. In A. C. Lo Bianco (Org.), Cultura da Ilusão (pp. 81-92). Rio de Janeiro, RJ: Contra Capa.

Torok, M. (1995). Doença do luto e fantasia do cadáver saboroso. In N. Abraham, \& M. Torok, A casca e o núcleo (pp.215-236). São Paulo, SP: Escuta.

Uchitel, M. (2001). Neurose traumática. São Paulo, SP: Casa do Psicólogo.

Winnicott, D. W. (2000). A reparação relativa à defesa organizada da mãe contra a depressão. In D. W. Winnicott, $D a$ pediatria à psicanálise: obras escolhidas (pp. 156-162). Rio de Janeiro, RJ: Imago. (Trabalho original publicado em 1958) 
Winnicott, D. W. (1999) Agressão, Culpa e Reparação. In:Winnicott, D. W. Privação e Delinquência (pp. 153-162). São Paulo, SP: Martins Fontes. (Trabalho original publicado em 1960).

Winnicott, D. W. (1994). O conceito de trauma em relação ao desenvolvimento do indivíduo dentro da família. In D. W. Winnicott, Explorações psicanalíticas (pp. 102-115). Porto Alegre, RS: Artes Médicas. (Trabalho original publicado em 1965).

Winnicott, D. W. (1994) O medo do colapso. In D. W. Winnicott, Explorações psicanalíticas (pp. 70-76). Porto Alegre, RS: Artes Médicas. (Trabalho original publicado em 1974).

Winnicott, D. W. (2000). Objetos transicionais e fenômenos transicionais. In D. W. Winnicott, Da pediatria à psicanálise: obras escolhidas (pp. 316-331). Rio de Janeiro, RJ: Imago. (Trabalho original publicado em 1951).

\section{Rafael Alves Lima}

Psicanalista, graduado em Psicologia pelo Instituto de Psicologia da Universidade de São Paulo - IP-USP. Mestre e doutorando em Psicologia Clínica pelo IP-USP. E-mail: rafael.alves.lima@usp.br

Endereço para envio de correspondência:

Rua Capote Valente, 1229 apto 73 - Pinheiros. CEP: 05409-003.

São Paulo - SP. Brasil.

Recebido30/06/2017

Reformulação 10/09/2017

Aprovado 18/09/2017

Received 06/30/2017

Reformulated $09 / 10 / 2017$

Approved 09/18/2017

Recebido 30/06/2017

Reformulado 10/09/2017

Aceptado 18/09/2017

Como citar: Alves Lima, R. (2017). Análise reparável e irreparável: o conceito psicanalítico de reparação na agenda da transição brasileira. Psicologia: Ciência e Profissão, 37(n. spe), 116-132. https://doi.org/10.1590/1982-3703090002017

How to cite: Alves Lima, R. (2017). Reparable and irreparable analysis: the psychoanalytic concept of reparation in the agenda of the brazilian transition. Psicologia: Ciência e Profissão, 37(n. spe), 116-132. https://doi.org/10.1590/1982-3703090002017

Cómo citar: Alves Lima, R. (2017). Análisis reparable e irreparable: el concepto psicoanalítico de reparación en la agenda de la transición brasileña. Psicologia: Ciência e Profissão, 37(n. spe), 116-132. https://doi.org/10.1590/1982-3703090002017 